\title{
Tuberculosis of Cervical Spine
}

\author{
Amir FZ* and Zullkifli A \\ Hospital Raja Permaisuri Bainun, Malaysia
}

Submission: November 20, 2017; Published: December 18, 2017

*Corresponding author: Amir FZ, Hospital Raja Permaisuri Bainun, Ipoh, Malaysia, Email: amirfarizzakaria@gmail.com

\begin{abstract}
Tuberculosis (TB) of spine is part of an extrapulmonary tuberculosis manifestation and is the most common form of skeletal tuberculosis. It affects mostly at the thoracic and lumbar region owing to its blood supply but uncommonly spreads to the cervical spine. This article describes a 67-year-old lady who presented with neck pain secondary to TB of cervical spine.
\end{abstract}

Keywords: Tuberculosis; Spine; Cervical

\section{Introduction}

Cervical TB spine is particularly rare, representing $3-5 \%$ of all spinal TB cases [1]. Mainstay treatments are usually chemotherapy with long duration of anti-tuberculosis medication. Only limited cases are indicated for surgery in which anterior approach to cervical is more favorable [2].

\section{Case Report}

We introduce a case of a 67-year-old lady initially presented in December 2016 with a complaint of neck pain radiating to both shoulders which resolved with physiotherapy and analgesia. However, she experienced worsening neck and interscapular pain in February 2017. This was accompanied by reduction of weight and appetite. Examination of the neck demonstrated localized tenderness to lower cervical and upper back. ROM of the neck was reduced. No palpable cervical lymph nodes were found. Neurological examination of the upper limbs and lower limbs were unremarkable with intact power, sensory and reflexes consistent with American Spinal Association (ASIA) Impairment scale grade $\mathrm{E}$.

Laboratory test revealed elevated Erythrocyte Sedimentation Rate of $40 \mathrm{~mm} / \mathrm{hr}$ and C-Reactive Protein of $24 \mathrm{mg} / \mathrm{l}$. Sputum acid fast bacilli (AFB) test and Mantoux test were both found to be normal.

Cervical radiograph showed lytic destruction of vertebral body of C6 and C7. MRI unveiled destruction of C6/C7 intervertebral disk, adjacent vertebral endplates erosion and spinal stenosis at this level. There were no surrounding collection or abscesses at this level. Chest radiograph did not show any nodular lesions suggestive of pulmonary tuberculosis.

Patient was electively planned for surgery; anterior cervical corpectomy of C6 and C7 with biopsy. She was positioned supine with head in extended position. Shoulders were strapped and pulled with minimal traction to allow visualization of the lower cervical on lateral radiographs. A small towel was also placed in between the scapula to drop the shoulders further.

The skin was prepared with povidone iodine, disposable drapes and iodine impregnated dressing. A standard anterior approach to the cervical was made from the left side of neck. The pathological cervical and intervertebral disk of $\mathrm{C} 6 / \mathrm{C} 7$ were removed by piecemeal and its specimen sent for histopathological examination (HPE). A Harms titanium mesh cage was implanted with autologous tricortical iliac bone graft packed into it. An anterior cervical plate spanning C5 to T1 was then placed.

\section{Discussion}

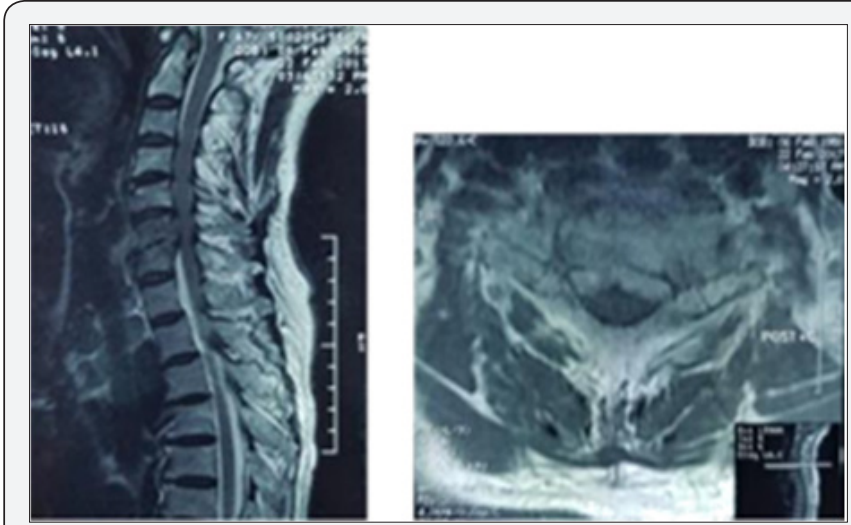

Figure 1: Preoperative MRI showing destruction of C6 and C7 vertebral body and intervertebral disk with spinal stenosis.

Tuberculosis is a great mimicker with multitude of clinical features and presentations. Initial diagnosis in this case was pyogenic (Figure $1 \& 2$ ) spondylodisciitis in view of increase 
inflammatory markers but negative sputum AFB and Mantoux test. It was the intraoperative HPE that revealed granulomatous inflammation with infiltrate lymphocytes, epitheliod macrophages and Langhans multinucleated giant cells which are typical of Mycobacterium tuberculosis.

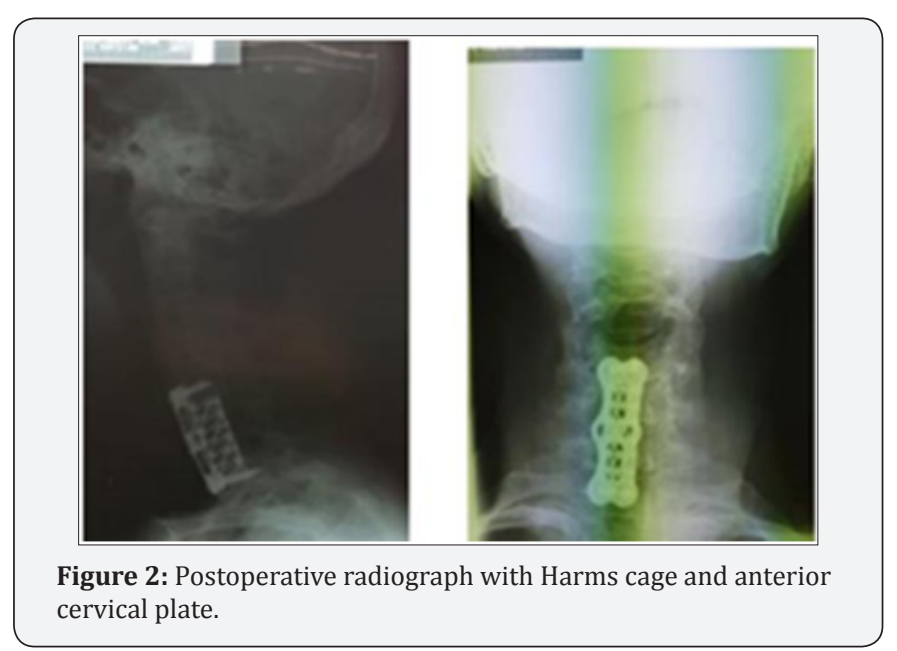

Tuberculosis is always secondary to a primary focus, often the pulmonary or genitourinary system [3]. TB spine is most commonly found in lower thoracic and upper lumbar regions. The middle thoracic and cervical region is less frequently involved. It commonly spreads by hematogenous dissemination of the bacillus both via arterial or venous. Infection of the paradiscal area is from the rich subchondral arterial plexus that is derived from the anterior and posterior vertebral arteries [4]. Infection of the vertebral body however is associated with intraosseous venous plexus derived from Batson paravertebral venous plexus. In most adult cases, TB spine results from reactivation of resting tubercle bacilli in quiescent lesions produced during an earlier infection.

Majority of TB spine are treated with anti-tuberculosis medication. British Medical Council and the Cochrane recommends treatment with appropriate anti- tuberculosis medication noting that there is insufficient evidence for routine use of surgery [5]. Surgeries however, are indicated in cases with neurological deficit, progressive deformity, pan vertebral lesions, and spinal TB that are refractory to medical therapy [6]. Other indications are severe pain from sequestered bone and disc, expanding abscess or instability [7].

The increasing neck pain she was experiencing was a result of destruction to the cervical spine giving rise to instability. The goal of surgery was to eradicate infection, obtain tissue biopsy to determine exact organism and provide stability.
In the Hong Kong procedure, the spine is approached anteriorly so that the area involved are dealt with directly. It provides best access for debridement, stabilization by grafting and facilitates rehabilitation, thus considered as the standard operative treatment when surgery is indicated $[8,9]$.

Hassan et al reported satisfactory outcome of single stage anterior autogenous iliac bone grafting and instrumentation in lower cervical spine tuberculosis involving 16 patients [10]. 12 showed complete recovery and 2 had marked improvements at an average of 38 months. All patients experienced reduction in pain postoperatively. Similarly, this patient had significant reduction in pain score after surgery.

\section{Conclusion}

One third of world's burden of tuberculosis are still found in South East Asia [11]. Health providers must have high index of suspicion as clinical presentation of tuberculosis are diverse. Mainstay treatment is anti-tuberculosis medication with surgery indicated in few.

\section{References}

1. He M, Xu H, Zhao J, Wang Z (2014) Anterior debridement, decompression, bone grafting, and instrumentation for lower cervical spine tuberculosis. Spine J 14(4): 619-627.

2. Mandavia R, Fox R, Meir A (2017) Atlantoaxial TB with paralysis: posterior only cervical approach with good result. JRSM Open 8(6): 1-4.

3. Catarino I, Robles D, Lopes D, Silva F, De Sousa C (2016) Cervical spinal epidural abscess due to Mycobacterium tuberculosis without osseous involvement. JBJS Case Connect 6: e79

4. Garg RK, Somvanshi DS (2011) Spinal tuberculosis: a review. J Spinal Cord Med 34(5): 440-454.

5. Jutte PC, Van Loenhout-Rooyackers JH (2006) Routine surgery in addition to chemotherapy for treating spinal tuberculosis. Cochrane Database Syst Rev 1: CD004532.

6. Hahn BS, Kim KH, Kuh SU, Park JY, Chin DK, et al. (2014) Surgical treatment in patients with cervical osteomyelitis: single institute's experiences. Korean J Spine 11(3): 162-168.

7. Dai LY, Jiang LS, Wang W, Cui YM (2005) Single stage anterior autogenous bone grafting and instrumentation in the surgical management of spinal tuberculosis. Spine (Phila Pa 1976) 30(20): 2342-2349.

8. Upadhyay SS, Sell P, Saji MJ, Sell B, Hsu LC (1994) Surgical management of spinal tuberculosis in adults: Hong Kong operation compared with debridement surgery for short and long term outcome of deformity. Clin Orthop Relat Res 302: 173-182.

9. Sadek AR, Wallage W, Jaiganesh T (2011) Cervical spine tuberculosis causing instability and neurological compromise. JRSM Short Rep 2(6): 47.

10. Hassan MG (2003) Anterior plating for lower cervical spine tuberculosis. Int Orthop 27(2): 73-77.

11. Nair N, Wares F, Sahu S (2010) Tuberculosis in WHO South East Asia Region. Bulletin of the World Health Organisation 88: 164. 


\section{Your next submission with Juniper Publishers will reach you the below assets}

- Quality Editorial service

- Swift Peer Review

- Reprints availability

- E-prints Service

- Manuscript Podcast for convenient understanding

- Global attainment for your research

- Manuscript accessibility in different formats ( Pdf, E-pub, Full Text, Audio)

- Unceasing customer service

Track the below URL for one-step submission https://juniperpublishers.com/online-submission.php 